\title{
Pattern-reversal visual evoked potentials as a diagnostic tool for ocular malingering
}

\author{
Potenciais visuais evocados por padrões reversos como uma ferramenta diagnóstica de simulação
}

Tarciana de Souza Soares ${ }^{1}$, Paula Yuri Sacal ${ }^{1}$, Adriana Berezovsky ${ }^{1}$, Daniel Martins Rocha ${ }^{1}$, Sung Eun Song Watanabe ${ }^{1}$, Solange Rios Salomão ${ }^{1}$

\begin{abstract}
Purpose: To investigate the contributions of transient pattern-reversal visual evoked potentials in the diagnosis of ocular malingering at a Brazilian university hospital. Methods: Adult patients with suspected malingering in one or both eyes were referred for visual evoked potential testing. Data from patients' medical records were reviewed and analyzed retrospectively. Data analysis included the distance optotype visual acuity based on a ETDRS retro-illuminated chart and the transient pattern-reversal visual evoked potential parameters of latency (milliseconds) and amplitude (microvolts) for the P100 component, using checkerboards with visual subtenses of $15^{\prime}$ and 60'. Motivations for malingering were noted.

Results: The 20 subjects included 11 (55\%) women. Patient ages ranged from 21 to 61 years ( mean $=45.05 \pm 11.76$ years; median $=49$ years). In 8 patients $(6$ women), both eyes exhibited reduced visual acuity with normal pattern-reversal visually evoked potential parameters (pure malingerers). The remaining $12 \mathrm{pa}$ tients ( 7 men) exhibited reduced vision in only 1 eye, with simulated reduced vision in the contralateral eye (exaggerators). Financial motivation was noted in 18 patients ( 9 men).

Conclusion: Normal pattern-reversal visually evoked potential parameters with suspected ocular malingering were observed in a 20 patient cohort. This electrophysiological technique appeared to be useful as a measure of visual pathway integrity in this specific population.
\end{abstract}

Keywords: Evoked potentials, visual/physiology; Malingering; Pattern recognition, visual; Vision disorders; Visual acuity

\section{RESUMO}

Objetivo: Investigar a contribuição dos potenciais visuais evocados por padrões reversos no diagnóstico de simulação de baixa de visão em um hospital universitário do Brasil.

Métodos: Um grupo de pacientes adultos com suspeita de simulação de baixa de visão em um ou ambos os olhos foi avaliado e os dados analisados retrospectivamente. Foram medidos: acuidade visual de optotipos informada para longe utilizando a tabela ETDRS, parâmetros dos potenciais visuais evocados por padrões reversos de latência (milissegundos) e amplitude (microvolts) para o componente P100 com estímulos de ângulos visuais de 15' e 60'. A motivação do paciente para a simulação foi anotada.

Resultados: Os participantes foram 20 indivíduos com 11 (55\%) do sexo feminino. A idade variou de 21 a 61 anos (média = 45,05 $\pm 11,76$ anos; mediana= 49 anos). Em 8 pacientes (6 mulheres) ambos os ol hos tinham acuidade visual reduzida com parâmetros dos potenciais visuais evocados por padrão reverso normais para ambos os olhos (simuladores puros). Uma subsérie separada de 12 pacientes (7 homens) tinha visão reduzida em apenas um olho e estavam simulando redução da visão no outro olho (exacerbadores). A motivação financeira foi observada em 18 pacientes (9 homens).

Conclusões: Parâmetros dos potenciais visuais evocados por padrões reversos normais foram encontrados neste grupo de 20 pacientes com suspeita de simulação. Esta técnica eletrofisiológica pode ser útil como uma medida da integridade do sistema visual nesta população de doentes.

Descritores: Potenciais evocados visuais/fisiologia; Simulação de doença; Reconhecimento visual de modelos; Transtornos da visão; Acuidade visual

\section{INTRODUCTION}

Functional vision loss (FVL) is a condition in which the patient's subjective visual symptoms do not corroborate the results of a clinical examination and diagnostic workup (1). In general, FVL is a clinical diagnosis made when the physician demonstrates that the patient's visual acuity (VA) is better than alleged ${ }^{(2)}$. The terminology associated with this condition varies considerably, and includes descriptors such as non-organic visual loss, psychogenic visual loss, malingering, hysterical visual loss, and ocular conversion reaction ${ }^{(1,3,4)}$. Decreased $\mathrm{VA}$, one of the most common functional complaints, may be either psychogenic or caused by malingering; with the former, subjects are unconscious of dissembling, whereas with the latter, subjects consciously dissemble the disease ${ }^{(5)}$.

In order to distinguish between a potential psychogenic disorder and malingering, it is important to conduct a thorough search for evidence and establish a well-documented understanding of the patient's context ${ }^{(6)}$. Malingering usually occurs when the patient seeks benefits associated with illness such as an evasion of criminal prose- cution, escape from military service, compensation from social security agencies or insurance companies, and/or access to unnecessary free medications or medical equipment ${ }^{(7,8)}$. In contrast, patients with psychogenic disorders tend to seek sympathy, family assistance, or social adjustment, and such cases usually present evidence of previous emotional trauma or stressful life events prior to the symptoms onset ${ }^{(7)}$.

A comprehensive examination must be performed to rule out organic causes of vision loss ${ }^{(9)}$. Measurement of visual function is a valuable step toward objectively explaining a patient's report of visual loss with no visible damage, and defending against subjective decision-making ${ }^{(10)}$. The visual evoked potential (VEP) test has been used to evaluate functionality of the visual pathway, and the pattern-reversal (PR)-VEP has been used as an objective assessment of VA. Previous studies have used the PR-VEP to objectively assess the visual pathway by comparing the results achieved with normative amplitude and latency values ${ }^{(11)}$.

The present study investigated the contributions of pattern-reversal transient VEPs to diagnose malingering in patients treated at a university hospital in Brazil.
Submitted for publication: October 20, 2015

Accepted for publication: May 15, 2016

${ }^{1}$ Laboratório de Eletrofisiologia Visual Clínica, Departamento de Oftalmologia e Ciências Visuais, Escola Paulista de Medicina (EPM), Universidade Federal de São Paulo (UNIFESP), São Paulo, SP, Brazil.
Funding: No specific financial support was available for this study.

Disclosure of potential conflicts of interest: None of the authors have any potential conflicts of interest to disclose.

Corresponding author: Solange Rios Salomão. Depto. de Oftalmologia e Ciências Visuais. Rua Botucatu, 821 - São Paulo, SP - 04023-062 - Brazil - E-mail: ssalomao@unifesp.br

Approved by the following research ethics committee: Escola Paulista de Medicina, Universidade Federal de São Paulo - UNIFESP (\#04171712.3.0000.5505). 


\section{METHODS}

This retrospective study was performed in the Laboratory of Clinical Electrophysiology of Vision, Universidade Federal de São Paulo (UNIFESP), Hospital São Paulo, São Paulo, Brazil. This study's procedures complied with the tenets of the Declaration of Helsinki, and the study's protocol was approved by the UNIFESP Committee on Ethics in Research.

All participants were asked about their clinical histories, with an emphasis on the visual loss characteristics (e.g., bilateral or unilateral) and onset (e.g., sudden or progressive). In an attempt to gather detailed information about the motivation for $\mathrm{FVL}$, questions were asked regarding medical leave from work, financial compensation for work accidents, and eventual use of medications for psychiatric disorders. The inclusion criteria were (1) unexplained visual loss according to findings from a previous ophthalmic exam (including visual acuity, refraction, biomicroscopy, intraocular pressure, direct and indirect fundoscopy evaluations) and (2) an age of $\geq 18$ years. The exclusion criterion was the presence of neurological disorders that might affect VEP recording (e.g., epilepsy, intracranial tumor).

\section{Procedures}

\section{Pattern-reversal visual evoked potential (PR-VEP)}

Transient PR-VEP recording was performed according to the recommendations of the International Society for Clinical Electrophysiology of Vision (ISCEV) ${ }^{(12)}$. PR-VEPs of each eye were obtained using electroencephalograph electrodes placed according to the 10-20 system. The active, reference, and ground electrodes were placed at $\mathrm{Oz}$, Fpz, and $\mathrm{Cz}$, respectively. Pattern-induced visual stimulation was provided by a pattern generator monitor with a mean luminance of $50 \mathrm{~cd} / \mathrm{m}^{2}$. The reversal frequency of the frame-locked pattern was $1.9 \mathrm{~Hz}$. At the viewing distance used in this study $(100 \mathrm{~cm})$, the display screen subtended angles of $17^{\circ} \times 17^{\circ}$ at the eye. Black and white checks with visual subtenses of $15^{\prime}$ and $60^{\prime}$ were used as stimuli, and the spatial frequency in the $45^{\circ}$ direction was calculated for both sizes of stimuli using a previously described formula ${ }^{(13)}$. The spatial frequencies (cycles/degree) were 0.44 and 1.79 for larger and smaller checks, respectively. These spatial frequencies corresponded to checkerboard resolution visual acuity thresholds of approximately 20/1400 for larger checks and 20/300 for smaller checks. Because the resolution acuity thresholds could exceed the optotype acuity scores by up to 1 octave, the minimum visual acuity required to evoke responses to the larger and smaller checks would be 20/700 and 20/150, respectively. The contrast was set to maximum, and the luminance remained constant.

Occipital responses were averaged using the UTAS E-3000 system (LKC Technologies, Inc., Gaithersburg, MD, USA). The average response to 100 reversals was analyzed. Latencies (ms) of the major positive component (P100) and the negative peaks (N75 and N135) were determined for both stimuli. The P100 latency was compared with normal values obtained in our laboratory after setting the $97.5^{\text {th }}$ percentile as the upper limit of normal(14). The Amplitude $(\mu \mathrm{V})$ was defined as the difference in potential between the N75 and P100 peaks. For each eye and using the two checkerboard sizes, VEPs were classified as normal, reduced amplitude, prolonged latency, and non-recordable. Normal PR-VEP parameters (P100 latency and amplitude) for both stimulus sizes and in both eyes were indicative of malingering.

To improve accuracy and compliance, a direct observation of the examined eye was performed, during which the subject was continuously asked to pay attention to the center of the stimulus monitor. In addition, evaluations were performed by experienced examiners and the developing average waveform was carefully observed.

\section{Visual acuity testing}

The participants' best corrected visual acuity was measured using a retro-illuminated ETDRS Chart with Tumble "E" optotypes; glasses and pinhole correction were used when necessary. Each score was recorded as the 4-m logarithm of the minimum angle of resolution (logMAR) acuity.

\section{Statistical analysis}

An unpaired t-test was used to compare age distributions between male and female subjects, and a p value $\leq 0.05$ was considered to be statistically significant.

\section{RESULTS}

The study subjects comprised 20 adults, including 11 (55\%) women, with ages ranging from 21 to 61 years (mean= $45.05 \pm 11.76$ years; median $=49$ years). The age distributions of men and women were similar; men's ages ranged from 21 to 58 years (mean $=44.44 \pm$ 11.91 years; median $=49$ years), and women's ages ranged from 30 to 61 years (mean $=45.54 \pm 12.19$ years; median $=49$ years). A total of 39 eyes were tested (1 female subject had a right ocular prosthesis).

Figure 1 shows the distributions of individual PR-VEP parameters (P100 latency and amplitude) for 8 patients who met the criteria for malingering. The demographics, complaints of visual loss, informed optotype acuities, and motivations for FVL are listed in table 1. Informed optotype acuity ranged from no light perception (NLP) to 20/50. Previous ocular or head trauma was present in 3 cases. Two female patients had no apparent cause of malingering; these cases most likely involved psychogenic functional visual loss, and one patient (patient \#4) was referred for psychiatric assessment.

Twelve patients had an organic background for visual loss in 1 eye and complained of visual loss in the contralateral eye; accordingly, they were classified as exaggerators. Table 2 presents the demographics, visual loss complaints, informed optotype acuities, and motivations of this particular group. For these 12 patients, the individual parameters (P100 latency and amplitude) of the eye without an organic background for visual loss are shown in figure 2. All patients in this group had a financial motivation for their visual loss. Visual acuity in the malingering eye ranged from 20/63 to NLP. In 5 cases, ocular trauma was the organic cause that led to malingering of the contralateral eye in an attempt to achieve personal gains from social security agencies. Representative PR-VEP data from both eyes of a 32-y ear-old man with a subjective VA of 20/250 in the right eye and ability to count fingers with the left eye are presented in figure 3 . The subject had experienced blunt trauma to his left eye and was suing his former employer for compensation benefits regarding his workplace injury.

\section{DISCUSSION}

In this cohort of patients from a public hospital in Brazil, transient PR-VEP testing was found to be highly sensitive for the identification and diagnosis of pure malingering ${ }^{(5)}$, as all eyes tested under the suspicion of malingering yielded normal PR-VEP amplitudes and latencies. A normal VEP result indicates a normal visual pathway with no organic cause of vision loss, and consequently, suggests malingering because of a specific motivation. It is important, however, to note that normal subjects might have employed changes in accommodation, a lack of attention, or meditation to consciously alter their VEPs to mimic significant visual or neurological lesions $s^{(5,15-18)}$. For example, a patient might not focus on the center of the screen or might close his/her eyes too frequently. However, these artifacts were controlled through a careful observation of patient behavior during testing, as described in another report ${ }^{(19)}$. In some cases, mainly those of patients who reported a lack of light perception, the use of flash VEPs might be considered to avoid the requirement for constant and steady eye fixation. However, flash VEPs are not sensitive to image blurring.

The majority of subjects in this study reported financial motivations for their reported ocular malingering (90\%). As in previous 

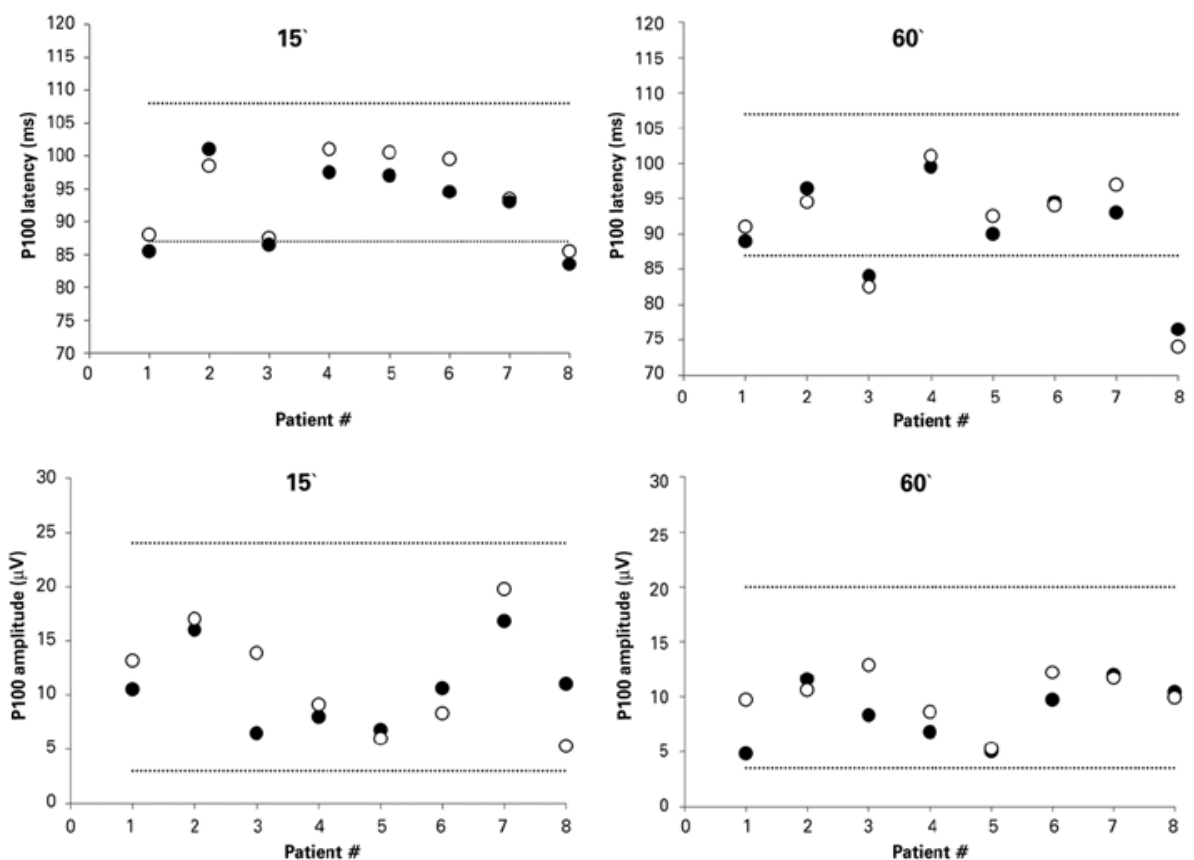

Figure 1. Transient pattern-reversal visual evoked potential parameters for check sizes of $15^{\prime}$ and 60 ', demonstrating $P 100$ latency (upper panels) and P100 amplitude (lower panels). Data were obtained from 8 patients with functional visual loss who were characterized as malingerers. Closed symbols represent right eye data; open symbols represent left eye data. Dotted lines indicate the lower and upper limits of normal as was determined in our own laboratory.

Table 1. Clinical characteristics of patients with malingering and normal VEP parameters in both eyes

\begin{tabular}{|c|c|c|c|c|c|c|c|}
\hline ID & Sex & Age (years) & Complaint of visual loss & Cause & VA RE & VA LE & Motivation \\
\hline 1 & $F$ & 33 & Binocular & None & $\mathrm{HM}$ & $20 / 160$ & Psychogenic \\
\hline 2 & M & 58 & Binocular & Corneal burn RE & $20 / 160$ & $20 / 50$ & Financial \\
\hline 3 & $\mathrm{~F}$ & 57 & Binocular & Bilateral diabetic retinopathy & $\mathrm{HM}$ & $20 / 125$ & Financial \\
\hline 4 & $\mathrm{~F}$ & 36 & Binocular & None & $20 / 200$ & NLP & Psychogenic \\
\hline 5 & $\mathrm{~F}$ & 56 & Right eye & Acute myocardial infarct & $20 / 160$ & $20 / 125$ & Financial \\
\hline 6 & M & 32 & Left eye & Blunt trauma LE & $20 / 250$ & $\mathrm{CF}$ & Financial \\
\hline 7 & $\mathrm{~F}$ & 60 & Binocular & None & $20 / 160$ & $20 / 125$ & Financial \\
\hline 8 & $\mathrm{~F}$ & 49 & Binocular & Head trauma with retinal detachment LE & $20 / 125$ & $20 / 200$ & Financial \\
\hline
\end{tabular}

$\mathrm{ID}=$ identification; $\mathrm{VA}=$ visual acuity; $\mathrm{F}=$ female; $\mathrm{M}=$ male; $\mathrm{RE}=$ right eye; $\mathrm{LE}=$ left eye; $\mathrm{HM}=$ hand motion; $\mathrm{NLP}=$ no light perception; $C F=$ counting fingers

Table 2. Clinical characteristics of 12 patients classified as exaggerators, with unilateral organic lesion: 9 malingering of the contralateral eye and 3 exaggerators of ipisilateral eye (patients 3, 7 and 9)

\begin{tabular}{cccccccccc}
\hline ID & Sex & Age & VA RE & VA LE & Complaint & VEP RE & VEP LE & Motivation & Ocular findings \\
\hline 1 & F & 34 & NLP & $20 / 630$ & Binocular & Non- detactable & Normal & Financial & Retinal atrophy post uveitis in RE \\
2 & F & 34 & $20 / 320$ & NLP & Binocular & Normal & Non-detectable & Financial & Infantile cataract in LE \\
3 & F & 30 & $20 / 400$ & $20 / 32$ & Monocular & Normal & Normal & Financial & Penetrating ocular trauma in RE \\
4 & F & 51 & Prosthesis & $20 / 63$ & Monocular & N/A & Normal & Financial & Ocular prosthesis in RE \\
5 & M & 37 & HM & LP & Binocular & Normal & Non-detectable & Financial & Macular scar post-chorioretinitis in LE \\
6 & M & 52 & NLP & CF & Monocular & Non-detectable & Normal & Financial & RCVO in RE \\
7 & M & 21 & NLP & $20 / 20$ & Binocular & Normal & Normal & Financial & Penetrating ocular trauma in RE \\
8 & M & 52 & NLP & $20 / 100$ & Binocular & Non-detectable & Normal & Financial & Phthisis bulbi in RE \\
9 & M & 48 & HM & $20 / 160$ & Binocular & Non-detectable & Normal & Financial & Retinal detachment in LE \\
10 & F & 61 & NLP & $20 / 400$ & Binocular & Non-detectable & Normal & Financial & Penetrating ocular trauma in RE \\
11 & M & 51 & NLP & $20 / 125$ & Binocular & Non-detectable & Normal & Financial & Blunt ocular trauma in RE \\
12 & M & 49 & NLP & $20 / 80$ & Binocular & Non-detectable & Normal & Financial & Penetrating ocular trauma in RE \\
\hline
\end{tabular}

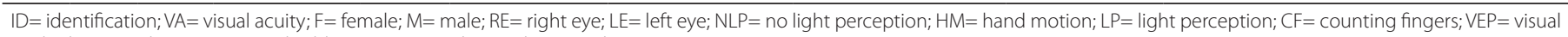
evoked potential; $\mathrm{N} / \mathrm{A}=$ non-applicable; $\mathrm{RCVO}=$ retinal central vein occlusion. 
studies, reliable PR-VEP data could be recorded in all patients with no observable physical damage to the anterior visual system who were included in the present study ${ }^{(9,20,21)}$. An earlier study of 4 children with functional visual losses and normal PR-VEP results reported psychological and social motivations as the major reasons for malingering ${ }^{(22)}$. PR-VEP testing assesses the integrity of visual stimulus conduction through the visual pathway, and a normal PR-VEP is thought to indicate pathway integrity; in addition, it is possible to
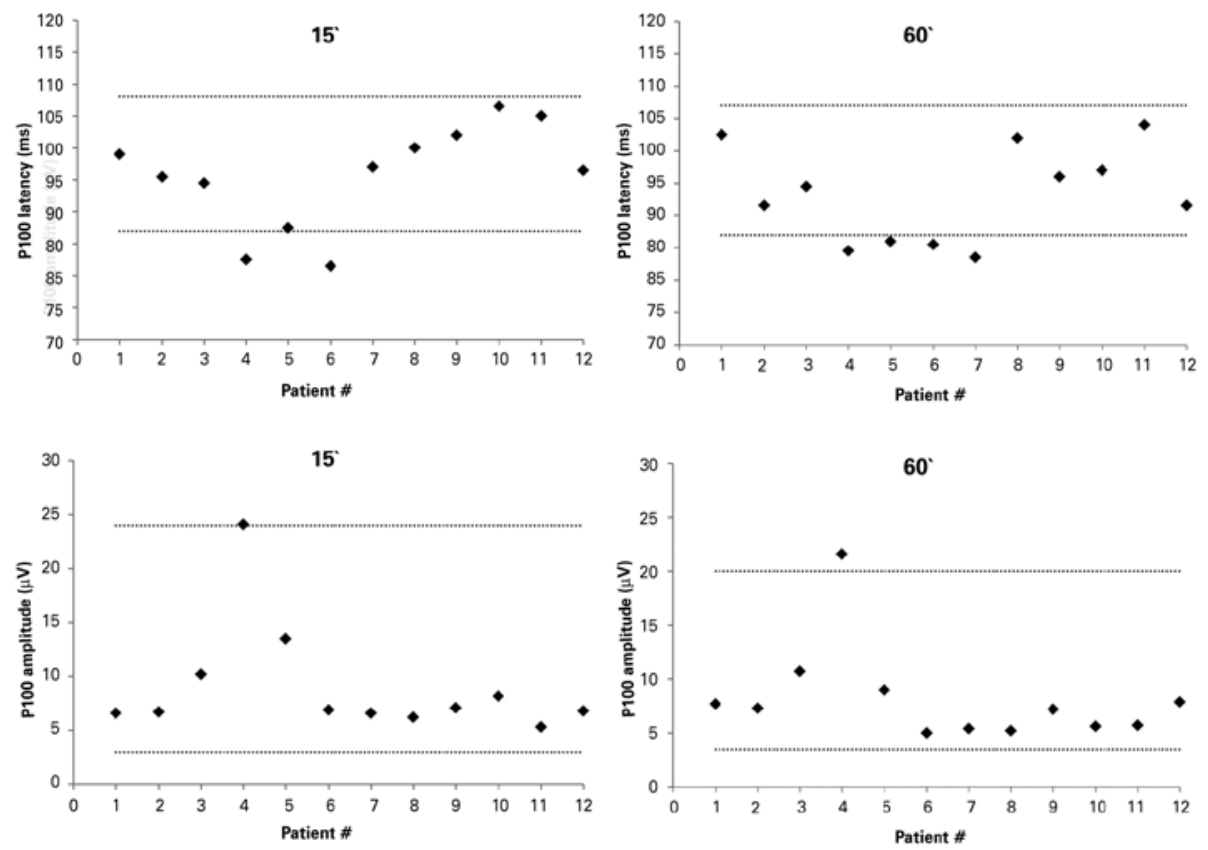

Figure 2. Transient pattern-reversal visual evoked potential parameters for check sizes of 15' and 60', demonstrating P100 latency (upper panels) and P100 amplitude (lower panels). Data obtained from 12 patients with functional visual loss who were characterized as malingerers and had one eye with an organic background. Data were obtained from the exaggerator eyes. Dotted lines indicate the lower and upper limits of normal as was determined in our own laboratory.

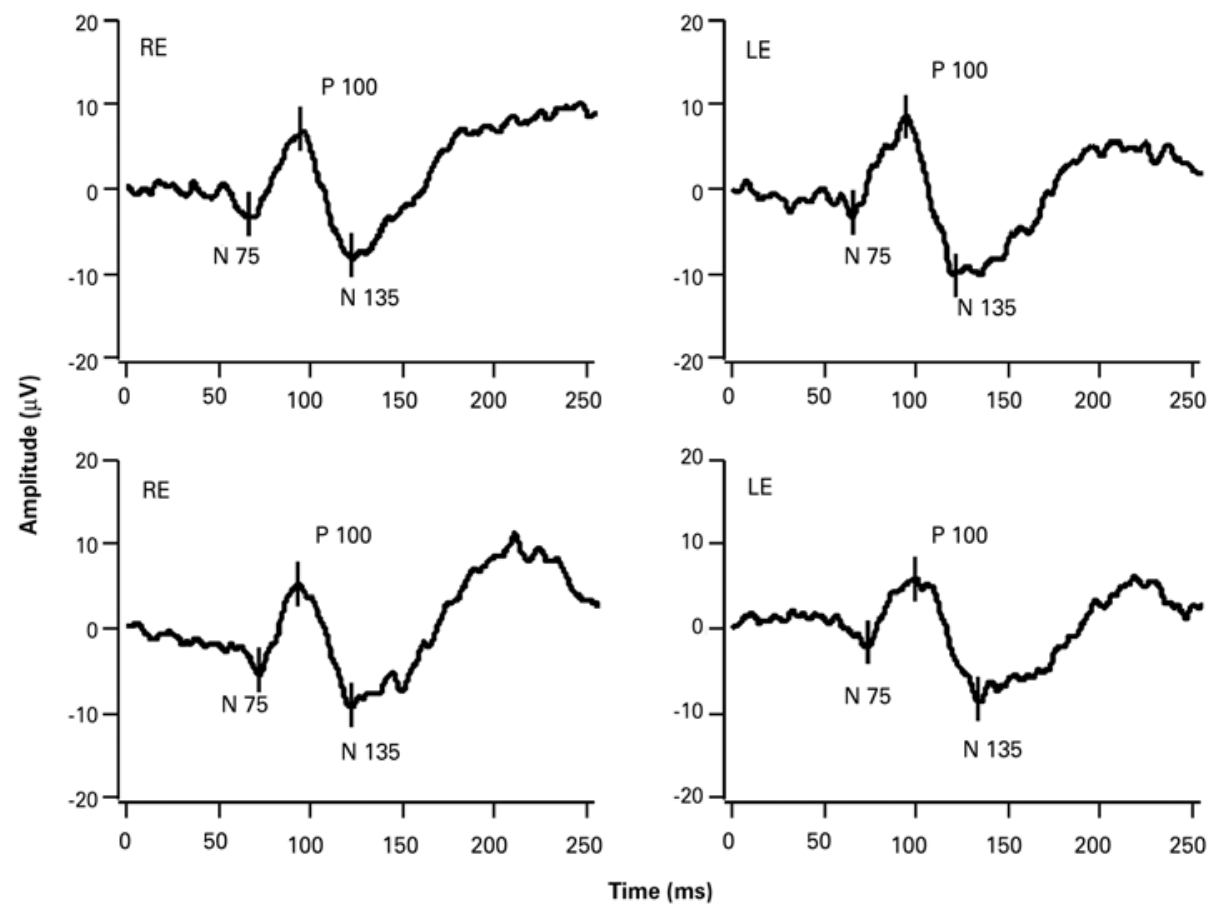

Figure 3. Transient pattern-reversal visually evoked potentials of the right and left eyes in a 32-year-old male (patient \#6) with informed visual acuity of $20 / 250$ in the right eye, the ability to count fingers with the left eye, and financial motivation. 
infer whether the informed acuity is or is not reliable. However, mild losses in visual acuity should be interpreted in light of clinical findings from an ophthalmic exam that includes careful anamnesis and detailed semiology. Furthermore, patients with a true reduction in visual acuity might exhibit normal VEP responses and could therefore be considered false dissemblers.

If the results of conventional tests are equivocal or an objective assessment of the visual system functional integrity is required, VEP testing can offer a more direct assessment of visual pathway integrity, particularly in the context of a simulated severe visual acuity loss such as that of light perception. Although the current study was not designed to measure objective visual acuity using ISCEV transient VEPS, such measurements could be reliably achieved using the previously described sweep-VEP technique(23). This type of electrophysiological assessment allows patients with complaints of unexplained reduced visual acuity to verify their complaints, assess the degree of an underlying disorder, and attempt to localize the site of the defect within the visual system ${ }^{(24)}$. PR-VEP might thus facilitate the detection or suspicion of malingering.

The major limitations of the present study were its retrospective design and its basis on a medical chart review; accordingly, the study lacked follow-up data that could confirm the subjects' malingering statuses. Furthermore, subject cooperation during the examination might have affected the PR-VEP outcomes. In this case series, many of the contributing factors associated with malingering, such as pre-existing trauma, physical illness, and pursuit of social benefits, were observed.

In conclusion, transient PR-VEP testing was found to be highly sensitive for the identification and diagnosis of pure malingering in a cohort of patients suspected of ocular malingering in a Brazilian hospital.

\section{REFERENCES}

1. Leavitt JA. Diagnosis and management of functional visual deficits. Curr Treat Options Neurol. 2006:8(1):45-51.

2. Chen CS, Lee AW, Karagiannis A, Crompton JL, Selva D. Practical clinical approaches to functional visual loss. J Clin Neurosci. 2007;14(1):1-7.

3. Lessel S. Nonorganic visual loss: what's in a name? Am J Ophthalmol. 2011;151(4):569-71.
4. Hamilton R, Bradnam MS, Dutton GN, Lai Chooi Yan AL, Lavy TE, Livingstone I, et al. Sensitivity and specificity of the step VEP in suspected functional visual acuity loss. Doc Ophthalmol. 2013;126(2):99-104

5. Gundogan FC, Sobaci G, Bayer A. Pattern visual evoked potentials in the assessment of visual acuity in malingering. Ophthalmology. 2007:114(12):2332-7.

6. Bass C, Halligan P. Factitious disorders and malingering: challenges for clinical assessment and management. Lancet. 2014;383(9926):1422-32. Comment in: Lancet. 2014;383 (9926):1368-9.

7. Nicholson TR, Kanaan RA. Conversion disorder. Psychiatry. 2009;8(5):164-9.

8. Incesu Al, Sobaci G. Malingering or simulation in ophthalmology-visual acuity. Int J Ophthalmol, 2011:4(5):558-66.

9. Xu S, Meyer D, Yoser S, Mathews D, Elfervig JL. Pattern visual evoked potential in the diagnosis of functional visual loss. Ophthalmology. 2001;108(1):76-81.

10. Bobak P, Khanna P, Goodwin J, Brigell M. Pattern visual evoked potentials in case of ambiguous acuity loss. Doc Ophthalmol. 1993;85(2):185-92.

11. Jeon J, Oh S, Kyung S. Assessment of visual disability using visual evoked potentials. BMC Ophthalmol. 2012:12:36.

12. Odom JV, Bach M, Brigell M, Holder GA, McCulloch DL, Tormene AM, et al. ISCEV standard for clinical visual evoked potentials. Doc Ophthalmol. 2010;120:111-9.

13. Fahle M, Bach M. Origin of the visual evoked potentials. In: Heckenlively JR, Arden GB (ed). Principles and practice of clinical electrophysiology of vision. $2^{\text {nd }}$ ed. Cambridge, USA: MIT Press; 2006. p. 207-34

14. Salomao SR, Sacai PY, Pereira JM, Berezovsky A. Pattern-reversal visually evoked potentials in healthy adults [abstract]. Invest Ophthalmol Vis Sci. 2006;47:5368.

15. Bumgartner J, Epstein C. Voluntary alteration of visual evoked potentials. Ann Neurol. 1982;12(5):475-8

16. Tan CT, Murray NM, Sawyers D, Leonard TJ. Deliberate alteration of the visual evoked potential. J Neurol Neurosurg Psychiatry. 1984;47(5):518-23.

17. Lovasik JV, Spafford M, Szymkiw M. Modification of pattern reversal VERs by ocular accommodation. Vision Res. 1985;25(4):599-608.

18. Douthwaite W, Connor H. Mental concentration and the pattern reversal visual evoked response. Optom Vis Sci.1989;66(1):61-5.

19. Röver J, Bach M. Pattern electroretinogram plus visual evoked potential: a decisive test in patients suspected of malingering. Doc Ophthalmol. 1987:66:245-51.

20. Steele M, Seiple WH, Carr RE, Klug R. The clinical utility of visual-evoked potential acuity testing. Am J Ophthalmol. 1989;108(5):572-7.

21. Barris MC, Kaufman DI, Barberio D. Visual impairment in hysteria. Doc Ophthalmol. 1992; 82:369-82.

22. Oyamada MK, Rodrigues-Alves CA, Barbante AM. Ambliopia funcional na idade escolar. Rev Bras Oftalmol. 1989:48(2):97-101.

23. Kurtenbach A, Langrová $H$, Messias A, Zrenner E, Jägle $H$. A comparison of the performance of three visual evoked potential-based methods to estimate visual acuity. Doc Ophthalmol. 2013:126:45-56.

24. Perlman I, Segev E, Mazawi N, Merhav-Armon T, Lei B, Leibu R. Visual evoked cortical potential can be used to differentiate between uncorrected refractive error and macular disorders. Doc Ophthalmol. 2001:102:41-62.

\title{
$42^{\circ}$ Congresso da Sociedade Brasileira de Retina e Vítreo
}

\author{
6 a 8 de abril de 2017 \\ Windsor Barra Hotel \\ Rio de Janeiro - RJ
}

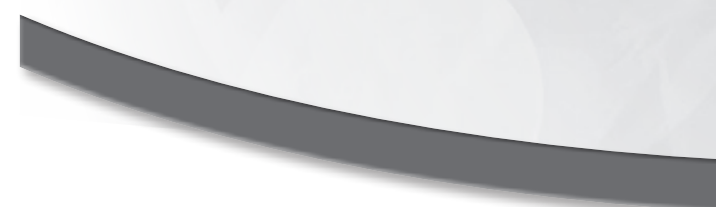

Informações:

Site: www.sbrv.org.br 